\title{
Comparison of Water Displacement and WinRHIZO Software for Plant Root Parameter Assessment
}

W. Pang, W. T. Crow, J. E. Luc, R. McSorley, and R. M. Giblin-Davis, Entomology and Nematology Department, K. E. Kenworthy, Agronomy Department, and J. K. Kruse, Environmental Horticulture Department, University of Florida, Gainesville 32611

\begin{abstract}
Pang, W., Crow, W. T., Luc, J. E., McSorley, R., Giblin-Davis, R. M., Kenworthy, K. E., and Kruse, J. K. 2011. Comparison of water displacement and WinRHIZO software for plant root parameter assessment. Plant Dis. 95:1308-1310.

Water-displacement and WinRHIZO root-scanning methods were compared for efficacy of root damage assessment. Results from both methods were similar and a highly significant relationship was found between the two methods in trial one $\left(r^{2}=0.9968, P<0.0001\right)$ and trial two $\left(r^{2}=0.9988, P<0.0001\right)$. Both protocols provide consistent root volume measurements; however, water displacement is preferred as an

economical method if a quick evaluation of a large amount of roots is essential. For a more detailed root morphological and architectural analysis, WinRHIZO root scanning provides additional information about several root parameters that cannot be measured by simple water displacement.
\end{abstract}

Plant-parasitic nematodes and other plant root pathogens cause root reductions and yield loss. Damage and changes to root morphology and architecture are usually observed in nematodeinfected plants (5-7). Feeding by some ectoparasitic nematodes typically causes root tips to stop growing. This, in turn, could reduce root length, volume, and surface area; capacity for water and nutrient uptake; and, eventually, plant biomass (5). Accurate measurement of root parameters is important for nematode damage assessment. Measurements of fresh and dry root weights are widely used methods to determine nematode damage to plant roots, and have been consistently used by nematologists $(2,6,7)$. Because feeding by nematodes often results in stunted roots, root length measurement has also been used as an important characteristic to determine nematode damage or plant tolerance (9). Root or shoot volume also has been used to estimate plant biomass because these measurements are highly correlated $(1,6)$, and volume measurement is much quicker to obtain.

In recent years, image analysis software has been designed for more detailed root morphological and architectural measurements. WinRHIZO root-scanning software (Regent Instruments Inc., Ottawa, ON Canada), which can provide a rapid measurement of multiple parameters such as root length, volume, surface area, diameter, tips, and crossings (4), has been widely used in plant stress research $(5,10)$. Although many methods are available for root measurements, selection of the most efficient and cost-effective method is important when evaluating a great amount of plant material. Plant breeders and nematologists have used the water-displacement method to measure root volume of a large amount of roots $(1,3,8)$. Bell et al. (1) and Harrington et al. (3) found that the water-displacement method can provide a quick, reproducible measure of shoot and root size and allow a very rapid assay of root growth. Schwartz et al. (10) reported that WinRHIZO root-scanning technology was an efficient method for screening turfgrass

Corresponding author: W. Pang, E-mail: wpang@vandals.uidaho.edu

Accepted for publication 28 March 2011.

doi:10.1094/PDIS-01-11-0026

(c) 2011 The American Phytopathological Society germplasm for tolerance to ectoparasitic nematodes. The objective of this study was to compare the water-displacement and WinRHIZO root-scanning methods for assessment of root volume.

\section{Materials and Methods}

To compare the efficacy of the water-displacement and WinRHIZO root-scanning methods, 204 root samples were measured in two sequential experimental trials in 2009. Root samples were collected from bermudagrass (Cynodon spp.) grown in a greenhouse at the University of Florida Turfgrass Envirotron in Gainesville. The roots of each sample were washed free of soil on an 853$\mu \mathrm{m}$ pore sieve, put into a $50-\mathrm{ml}$ plastic tube, and submerged in water. Finer roots were separated from soil and collected into the plastic tube by submerging and shaking the $853-\mu \mathrm{m}$ pore sieve in tap water. The roots of each sample were scanned using WinRHIZO root-scanning equipment and software, and root volumes were measured from the scanned images. After scanning, roots in each sample were collected and surface dried by rolling them into a paper towel. For the water-displacement method, the roots were then submerged into a $10-\mathrm{ml}$ graduated cylinder filled with $5 \mathrm{ml}$ of water. The volumes of the water in the cylinder were recorded before and after submerging the roots into the cylinder. The volume of roots was calculated as follows: root volume $=$ volume of the water after submerging the roots into the cylinder - volume of the water before submerging the roots. Regression analysis was conducted to compare the results of the two methods, and statistical analysis was conducted using SAS programs (SAS Institute, Cary, NC).

\section{Results and Discussion}

The root volume of each sample was compared using the WinRHIZO root-scanning method and the water-displacement protocols. Results from both methods were similar and produced a highly significant linear regression relationship in trial one $\left(r^{2}=\right.$ $0.9968, P<0.0001)$ (Fig. 1A) and trial two $\left(r^{2}=0.9988, P<\right.$ 0.0001) (Fig. 1B). The results provided by the two methods were extremely consistent, with similar lines and slopes near 1.0 (Fig. 1). This indicated that both methods can provide consistent root volume measurements, which could be used for assessing some ectoparasitic nematode feeding damage $(1,3,8)$. For endoparasitic nematodes, dry root weight measurements may be necessary be- 


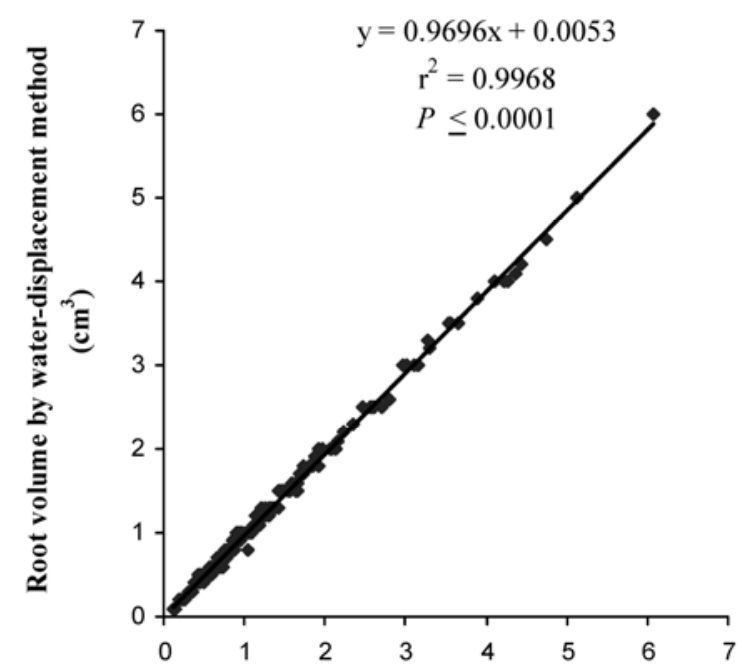

Root volume by WinRHIZO root-scanning method $\left(\mathrm{cm}^{3}\right)$

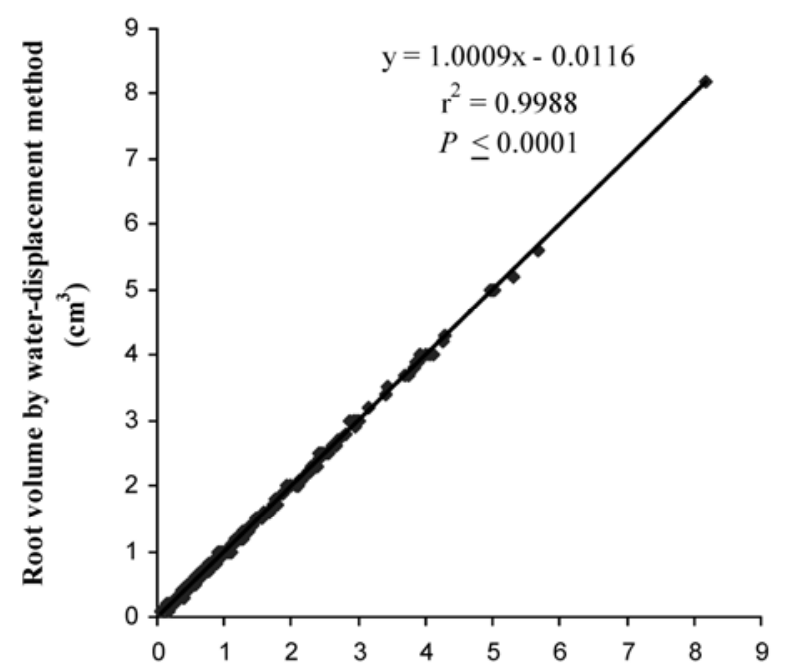

Root volume by WinRHIZO root-scanning method $\left(\mathrm{cm}^{3}\right)$

Fig. 1. Regression relationship between the root volumes of bermudagrass measured by the water-displacement method and WinRHIZO root-scanning method in two tests. A, Test one and B, test two.

cause nematode numbers per gram of dry root is an accepted standard for nematode damage evaluation (2).

The average times required to measure a sample using each method were recorded (i.e., $142 \mathrm{~s}$ for scanning and $111 \mathrm{~s}$ for water displacement; Table 1). The water-displacement method saved half a minute for each sample. Furthermore, a significant linear regression relationship between the times used by both methods was found in trial one (Fig. 2A) and trial two (Fig 2B), respectively. Although both water-displacement and WinRHIZO root-scanning methods provided similar measurements of root volume, for root samples with very small volume (less than $1 \mathrm{~cm}^{3}$ ), the estimated error introduced by reading the graduated cylinder (the minimum unit is $0.1 \mathrm{~cm}^{3}$ ) could make the measurements less accurate than with the root-scanning method. However, water displacement is more efficient for measurement of large root samples that do not fit into the scanning tray, because division into multiple subsamples for scanning and increased handling time are required. The waterdisplacement method could only measure the total volume of a sample but the root-scanning method measured additional, informative parameters, including length, length/volume, project area, surface area, diameter, crossings, tips, and forks. Root length, surface area, and number of tips are important indicators of water and nutrient uptake potential, and root diameter is an important parameter for rhizosphere modeling (4). Therefore, the use of Win-
Table 1. Mean time used for measuring one root sample by the WinRHIZO root scanning and water displacement methods in two tests

\begin{tabular}{lcc}
\hline \multirow{2}{*}{ Method } & \multicolumn{2}{c}{ Mean time for one sample (seconds) ${ }^{\mathbf{z}}$} \\
\cline { 2 - 3 } & Test $\mathbf{1}$ & Test $\mathbf{2}$ \\
\hline WinRHIZO root scanning & $131 \mathrm{a}$ & $153 \mathrm{a}$ \\
Water displacement & $105 \mathrm{~b}$ & $117 \mathrm{~b}$ \\
\hline
\end{tabular}

${ }^{\mathrm{z}}$ Means within a column followed by the same letter are not different $(P \leq$ 0.05), by Fisher's protected least significant difference test.
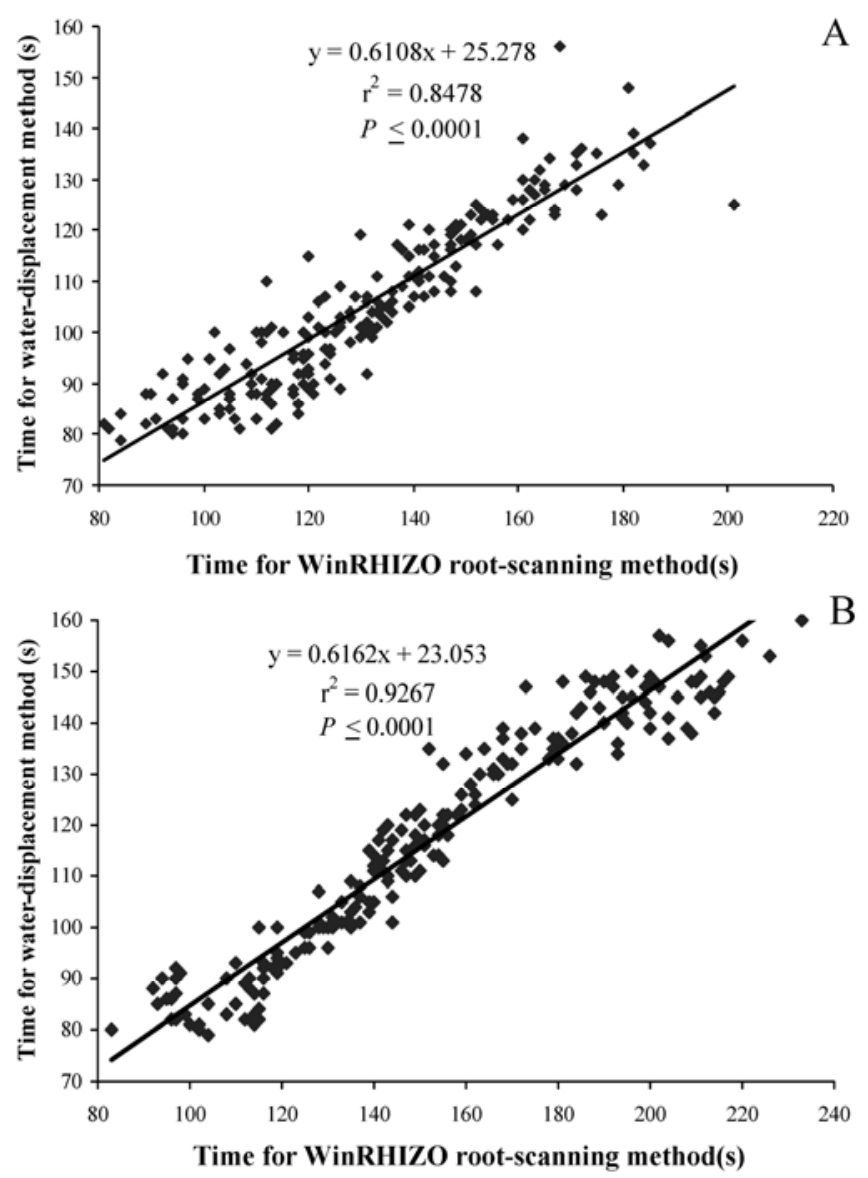

Fig. 2. Regression relationship between the times used for measuring one root sample by the water-displacement method and WinRHIZO root-scanning method in two tests. A, Test one and B, test two.

RHIZO is beneficial for use in detailed root architecture and plant stress or physiology studies. In contrast, the root-scanning method is initially more expensive because special software and equipment are needed. Therefore, the root-scanning method is preferred for root measurement of small root samples when the software and equipment are available, and water displacement is an economical method to gain limited information if root-scanning equipment and software are not available.

Each method has its advantages depending on the purpose of the study and the availability of equipment. If a quick evaluation of root damage for a large root sample is essential, water displacement is an accurate and low-cost method. However, if more detailed root morphological and architectural analysis is required, then the use of WinRHIZO software is recommended.

\section{Acknowledgments}

We thank the United States Golf Association for funding and the working group of W. T. Crow for their technical support for this study.

\section{Literature Cited}

1. Bell, S. S., Watzin, M. C., and Coull, B. C. 1978. Biogenic structure and its effect on the spatial heterogeneity of meiofauna in a salt marsh. J. Exp. Ma- 
rine Biol. 35:99-107.

2. Fallas, G. A., Sarah, J. L., and Fargette, M. 1995. Reproductive fitness and pathogenicity of eight Radopholus similis isolates on banana plants (Musa AAA cv. Poyo). Nematropica 25:135-141.

3. Harrington, J. T., Mexal, J. G., and Fisher, J. T. 1994. Volume displacement provides a quick and accurate way to quantify new root production. Tree Planters' Notes 45:121-124.

4. Himmelbauer, M. L., Loiskandl, W., and Kastanek, F. 2004. Estimating length, average diameter and surface area of roots using two different image analyses systems. Plant Soil 260:111-120.

5. Luc, J. E., Crow, W. T., Stimac, J. L., Sartain, J. B., and Giblin-Davis, R. M. 2006. Influence of Belonolaimus longicaudatus on nitrate leaching in turf. J. Nematol. 38:461-465.
6. Pang, W., Hafez, S. L., and Palanisamy, S. 2009. Pathogenicity of Meloidogyne hapla on onion. Nematropica 39:207-215.

7. Pang, W., Hafez, S. L., and Palanisamy, S. 2009. Pathogenicity of Pratylenchus penetrans on onion. Nematropica 39:35-46.

8. Quesenberry, K. H., and Dunn, R. A. 1977. Differential responses of Hemarthia genotypes to sting nematodes in a greenhouse screening trial. Soil Crop Sci. Soc. Fla. 37:58-61.

9. Rawsthorne, D., and Brodie, B. B. 1986. Relationship between root growth of potato, root diffusate production, and hatching of Globodera rostochiensis. J. Nematol.18:379-384.

10. Schwartz, B. M., Kenworthy, K. E., Crow, W. T., Ferrell, J. A., Miller, G. L., and Quesenberry, K. H. 2010. Variable responses of zoysiagrass genotypes to the sting nematode. Crop Sci. 50:723-729. 